\title{
PENGARUH PEMBERIAN AROMA TERAPI LEMON (CYTRUS) TERHADAP PENURUNAN NYERI DISMENORE
}

\author{
Nurpratiwi $^{1^{*}}$,Fajar Yousriatin ${ }^{2}$ Utin Maulidiyah $^{3}$ \\ 1.2.3 Sekolah Tinggi Ilmu Kesehatan Yayasan Rumah Sakit Islam Pontianak
}

Koresponden:

Nurpratiwi: Keperawatan Medikal Bedah, STIKes Yarsi Pontianak, Jl. Panglima A'im No. 1 Pontianak Timur, Pontianak, Kalimantan Barat - 78232, Email : nurpratiwi466@gmail.com

\begin{abstract}
ABSTRAK
Latar Belakang : Nyeri haid atau dismenore merupakan kram yang menyakitkan yang berasal dari uterus yang terjadi selama menstruasi dan merupakan satu penyebab paling umum nyeri panggul dan gangguan menstruasi. Penyebab utama dismenore primer adalah karena terjadinya peningkatan atau produksi yang tidak seimbang dari prostaglandin endometrium selama menstruasi. Zat limeone dalam lemon (citrus) akan mengontrol prostaglandin dan mengurangi rasa nyeri.Tujuan : Tujuan penelitian untuk mengetahui apakah pemberian aroma terapi lemon (Cytrus) berpengaruh terhadap penurunan nyeri dismenore pada siswi di SMAN 1 Sungai Ambawang. Metode : Penelitian ini menggunakan metode kuantitatif dengan menggunakan desain quasi experiment (eksperimen semu) dengan rancangan pre and post tes with control yaitu melakukan intervensi pada dua kelompok dengan jumlah responden sebanyak 34 responden dan masing-masing kelompok terbagi menjadi 17 responden. Analisa bivariat menggunakan uji menggunakan uji Wilcoxon. Hasil : Hasil penelitian menunjukkan terdapat pengaruh pemberian aroma terapi lemon (Cytrus) terhadap penurunan nyeri dismenore dengan nilai $\mathrm{p}<0,005$ yaitu $\mathrm{p}: 0,000$ yang berarti Ha diterima Ho ditolak. Kesimpulan : Terdapat pengaruh antara pemberian aroma terapi lemon (Cytrus) terhadap penurunan nyeri dismenore.
\end{abstract}

Kata Kunci : Pemberian Aroma Terapi Lemon, Penurunan Nyeri Dismenore

\begin{abstract}
ABSTRAC
Background: Menstrual pain or dysmenorrhea are painful cramps from the uterus that occur during menstruation and are one of the most common causes of pelvic pain and menstrual disorders. The main cause of primary dysmenorrhea is due to an increase or unbalanced production of endometrial prostaglandins during menstruation. The substance limeone in lemon (cytrus) will control prostaglandins and reduce pain. Purpose: The purpose of this study was to determine whether the administration of lemon aromatherapy (Citrus) affected the reduction in dysmenorrhea pain among female students at SMAN 1 Sungai Ambawang. Method: This research uses a quantitative method using a quasi-experimental design (quasi-experimental) with a pre and post-test with control design that is to intervene in two groups with a total of 34 respondents and each group is divided into 17 respondents. Bivariate analysis using test using Wilcoxon test. The results : results showed that there was an influence of giving lemon aromatherapy (Citrus) to the reduction of dysmenorrhea pain with a value of $p<0.005$, which is $p: 0,000$, which means Ha was accepted Ho was rejected. Conclusion: There is an influence between the administration of lemon aromatherapy (Citrus) on the decrease in dysmenorrhea pain.
\end{abstract}

Keyword : 


\section{PENDAHULUAN}

Wanita normal akan mengalami menstruasi atau haid yang berlangsung setiap belunnya. Menstruasi meluruhnya jaringan endometrium yang disebabkan tidak adanya telur matang yang dibuahi oleh sperma. Haid merupakan kondisi yang wajar dan alami pada semua wanita yang normal. Namun, pada kenyataanya banyak wanita menderita masalah haid berupa nyeri haid atau dismenore (Bezuidenhout \& Mahlaba, 2018).

Dismenore merupakan kram yang menyakitkan dan berasal dari uterus yang terjadi selama menstruasi serta merupakan salah satu penyebab paling umum nyeri panggul dan gangguan menstruasi (Petraglia et al., 2017). Rasa sakit muncul dalam beberapa jam sebelum atau selama menstruasi berlangsung yang kurang lebih 48 hingga 72 jam. Kram berasal dari kontraksi di rahim. Kontraksi ini normal selama proses menstruasi dan biasanya pertama dirasakan ketika perdarahan dimulai (Abreu-Sánchez et al., 2020).

Menurut WHO, wanita yang mengalami disminore mencapai 1.769 .425 jiwa (90\%) dengan $10-15 \%$ mengalami dismenore berat. Sebanyak $90 \%$ dari remaja wanita diseluruh dunia menderita masalah saat menstruasi dan lebih dari $50 \%$ wanita mengalami dismenore (Berkley, 2013). Angka kejadian dismenore di Indonesia mencapai $\quad 64,25 \%$ dimana $54,89 \%$ merupakan dismenore primer dan 9,36\% dismenore sekunder (Larasati \& Alatas, 2016).

Terdapat beberapa faktor penyebab dismenore salah satunya adalah usia. Usia 12-25 tahun hormon prostaglandin yang terdapat pada remaja putri terkadang masih belum stabil. Hormon yang belum stabil mengakibatkan gangguan keseimbangan prostaksiklin saat menstruasi. Kondisi ini dapat menyebabkan kontraksi miometrium yang dapat menimbulkan iskemia miometrium dan hiperkontraktivitas uterus. Kondisi inilah yang dapat menimbulkan nyeri dismenore (Vilšinskaitè et al., 2019).

Banyak cara untuk mengatasi permasalahan dismenore baik secara medis maupun secara non medis. Penggunaan metode medis berupa pemberian obatobataan sering diberikan kepada perempuan yang mengalami dismenore. Namun, pemberian obat-obatan medis cenderung menimbulkan efek samping yang tidak diinginkan. Oleh karena itu, diperlukan metode yang dapat meminimalisir efek samping yang muncul dan metode non medis atau terapi komplementer menjadi alternatif pilihan tersebut (Abubakar et al., 2020). Banyak sekali terapi komplementer yang dapat kita gunakan dalam mengatasi dismenore. Terapi bantalan hangat atau berendam di air hangat dapat mengurangi kram, meningkatkan vasodilatasi dan relaksasi otot. Biofeedback (terapi pengontrolan diri sendiri), stimulus elektrik transkutan pada saraf (TENS), relaksasi progresif, hatha yoga, akupuntur, meditasi dan aromaterapi untuk mengurangi rasa tidak nyaman pada menstruasi (Sharghi et al., 2019).

Salah satu aromaterapi yang dapat mengatasi masalah nyeri yang muncul adalah aromaterapi lemon. Aromaterapi lemon digunakan untuk meningkatkan mood dan mengurangi rasa marah. Minyak aromaterapi lemon mempunyai kandungan limeone 6680, granil asetat, netrol, tripne $6-14 \%, \alpha$ pinene 1-4 dan mrcyne (Ali et al., 2015). Limeone adalah komponen utama dalam senyawa kimia jeruk yang dapat menghambat sistem kerja prostaglandin sehingga dapat mengurai nyeri dan mengurangi rasa sakit (Namazi et al., 2014) Aromaterapi lemon 
(cytrus) dapat menurunkan nyeri dan cemas. Zat yang terdapat dalam lemon salah satunya adalah linalool yang berguna untuk menstabilkan system saraf sehingga dapat menimbulkan efek tenang bagi siapapun yang menghirupnya (Al-Quadh et al., 2018).

Ada banyak teknik untuk menggunakan aromaterapi dalam bidang ilmu kesehatan. Salah satu teknik menggunakan aromaterapi dapat berupa tehnik Steam inhalation. Steam inhalation adalah teknik menghirup uap hangat dari air mendidih. Selain itu steam inhalation juga salah satu teknik yang cukup mudah digunakan karena hanya memerlukan air panas, baskom, essential oil, dan handuk (Jo \& Lee, 2018).

Salah satu aromaterapi yang dapat mengatasi masalah nyeri yang muncul adalah aromaterapi lemon. Aromaterapi lemon digunakan untuk meningkatkan mood dan mengurangi rasa marah . Minyak aromaterapi lemon mempunyai kandungan limeone 6680, granil asetat, netrol, tripne 6-14\%, $\alpha$ pinene 1-4 dan mrcyne (Ali et al., 2015). Limeone adalah komponen utama dalam senyawa kimia jeruk yang dapat menghambat sistem kerja prostaglandin sehingga dapat mengurai nyeri dan mengurangi rasa sakit (Namazi et al., 2014) Aromaterapi lemon (cytrus) dapat menurunkan nyeri dan cemas. Zat yang terdapat dalam lemon salah satunya adalah linalool yang berguna untuk menstabilkan system saraf sehingga dapat menimbulkan efek tenang bagi siapapun yang menghirupnya (Al-Quadh et al., 2018).

Berdasarkan hasil wawancara studi pendahuluan yang dilakukan pada tanggal 12 Maret 2019 pada 15 remaja siswi di SMAN 1 SUNGAI AMBAWANG, didapatkan bahwa 12 siswi mengalami nyeri dismenore pada menstruasi hari pertama sampai hari ke-tiga, sedangkan 3 orang siswi lainnya tidak mengalami nyeri saat menstruasi. Peneliti juga menanyakan kepada 12 siswi yang mengalami dismenore terkait penangan apa saja yang biasa dilakukan ketika mengalami dismenore, dari 12 siswi tersebut 6 orang siswi mengatakan tidak melakukan penanganan apa-apa ketika mengalami dismenore, 3 siswi mengatakan melakukan penanganan ketika dismenore dengan mengkonsumsi obat.

Berdasarkan penjelasan di atas, maka peneliti akan melakukan penelitian "Pengaruh Pemberian Aroma Terapi Lemon (Cytrus) Terhadap Penurunan Nyeri Dismenore Pada Siswi Remaja di SMAN 1 SUNGAI AMBAWANG".

\section{METODE}

Jenis penelitian yang digunakan dalam penelitian ini adalah kuantitatif dengan menggunakan desain quasi experiment (eksperimen semu) yaitu dengan rancangan pre and post tes with control group. yaitu melakukan intervensi pada dua kelompok. Kelompok intervensi diberikan relaksasi menggunakan aromaterapi lemon dengan teknik steam inhalasi dan satu kelompok control diberikan relaksasi tanpa menggunakan aromaterapi lemon dengan teknik steam inhalasi. Pengambilan sampel menggunakan cara non probability sampling dengan metode purposive sampling. Jumlah sampel berjumlah 34 orang dengan kelompok intervensi dan kelompok kontrol masingmasing berjumlah 34 orang. Adapun kriteria inklusi pada penelitian ini adalah siswi remaja SMAN 1 Sungai Ambawang yang mengalami disemonere dengan skala nyeri 16 , tidak mengalami gangguan pada indra penciuman dan pernapasan serta kooperatif. Uji bivariat menggunakan uji Wilcoxon Signed Rank Test. 


\section{HASIL}

\section{Karateristik Responden}

Tabel 1 Distribusi Karakteristik responden berdasarkan usia dan usia pertama kali menstruasi (menarche) di SMA N 1

\begin{tabular}{lcc}
\hline \multicolumn{1}{c}{ Karakteristik } & $\mathrm{f}$ & $\%$ \\
\hline Usia & & \\
15 & 5 & 14,7 \\
16 & 16 & 47,1 \\
17 & 11 & 32,4 \\
18 & 2 & 5,9 \\
\hline Total & 34 & 100,0 \\
\hline
\end{tabular}

\begin{tabular}{lcc}
\hline Karkteristik & $\mathrm{f}$ & $\%$ \\
\hline Menarche & & \\
11 & 6 & 17,6 \\
12 & 10 & 29,4 \\
13 & 13 & 38,2 \\
14 & 5 & 14,7 \\
\hline Total & 34 & 100,0 \\
\hline
\end{tabular}

Berdasarkan tabel 1 diatas, dari 34 responden menunjukkan bahwa usia terbanyak dalam penelitian ini ber usia 16 tahun sebesar $(47,1 \%)$ dan usia pertama kali menstruasi (menarche) terbanyak yaitu berusia 13 tahun sebesar $(38,2 \%)$.

Tabel 2 Distribusi tingkat nyeri menstruasi siswi di SMA N 1 Sungai Ambawang tahun 2019

\begin{tabular}{|c|c|c|}
\hline Tingkat nyeri & $\mathrm{f}$ & $\%$ \\
\hline Ringan & 19 & 55,9 \\
\hline Sedang & 15 & 44,1 \\
\hline Total & 34 & 100,0 \\
\hline
\end{tabular}

menunjukkan bahwa dari 34 responden yang mengalami nyeri saat menstruasi, nyeri terbanyak yang dirasakan adalah nyeri ringan yaitu sebanyak $19(55,9 \%)$.
Tabel 3 Distribusi tingkat nyeri pre dan post test kelompok intervensi siswi di SMA N 1 Sungai Ambawang tahun 2019

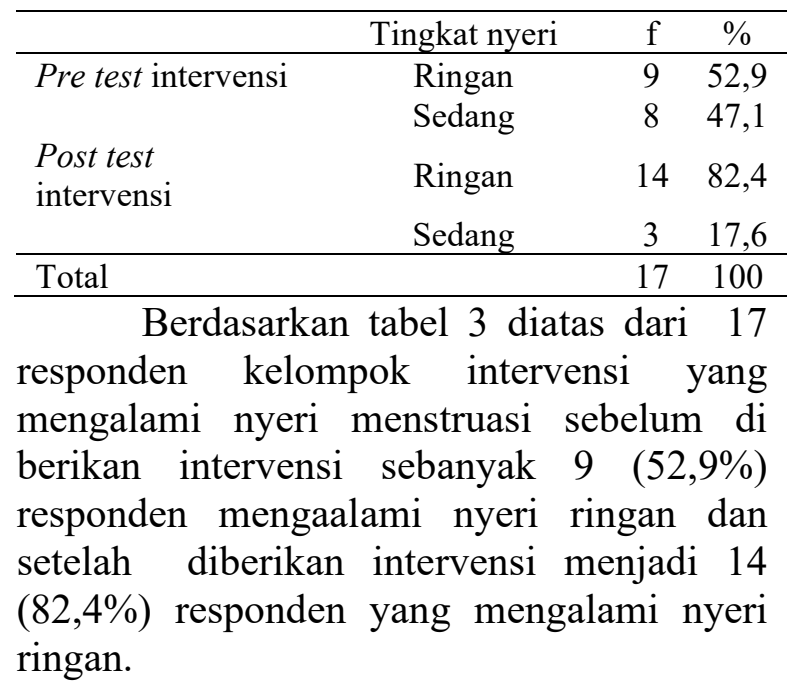

Tabel 4 Distribusi tingkat nyeri pre dan post test kelompok kontrol siswi di SMA N 1 Sungai Ambawang tahun 2019

\begin{tabular}{lccc}
\hline & Tingkat nyeri & $\mathrm{f}$ & $\%$ \\
\hline Pre test kontrol & Ringan & 11 & 64,7 \\
& Sedang & 6 & 35,3 \\
Post test kontrol & Ringan & 11 & 64,7 \\
& Sedang & 6 & 35,3 \\
\hline Total & & 17 & 100 \\
\hline \multicolumn{2}{c}{ Berdasarkan } & & 17 \\
& &
\end{tabular}

responden kelompok kontrol yang mengalami nyeri menstruasi sebelum dan sesudah diberikan intervensi sebanyak 22 ( $64,7 \%$ ) responden yang mengalami nyeri ringan.

Tabel 5 Hasil uji Wilcoxon Signed Ranks Test tingkat nyeri menstruasi Pre test dan Post test kelompok intervensi dan kelompok kontrol di SMA N 1 Sungai Ambawang tahun 2019

\begin{tabular}{lcc}
\hline & Mean & Nilai $\mathrm{p}$ \\
\cline { 2 - 3 } & 3.00 & 0,025 \\
$\begin{array}{c}\text { Pre test \& post test } \\
\text { intervensi }\end{array}$ & & \\
\hline
\end{tabular}



Pre test \& post test kontrol
0.00
1,000

Berdasarkan tabel 5 diatas, menunjukan hasil bahwa nilai tingkat nyeri menstruasi pre test \& post test kelompok intervensi, didapatkan nilai p value $0,025<$ 0,05 maka dapat disimpulkan bahwa ada perbedaan yang signifikan dari skala nyeri pre test and post test pada kelompok intervensi. Sedangkan untuk tingkat nyeri menstruasi pre test \& post test kelompok kontrol, didapatkan nilai $\mathrm{p}$ value $1,000>0,05$ maka disimpulkan bahwa tidak ada ada perbedaan yang signifikan dari skala nyeri pre test and post test pada kelompok kontrol.

\section{PEMBAHASAN}

Hasil penelitian menunjukan nyeri menstruasi pada siswi sekolah menengah atas negeri 1 sungai ambawang yang dilakukan terhadap 17 responden kelompok kontrol terdapat perbedaan secara signifikan antara nilai nyeri menstruasi sebelum diberikan intervensi teknik relaksasi steam inhalation dengan menggunakan aromaterapi lemon dengan nilai $\mathrm{p}$ value 0,025 lebih kecil dari 0,05, maka Ha diterima yang artinya ada pengaruh pemberian aromaterapi lemon (citrus) terhadap penurunan nyeri menstruasi. Sedangkan pada tabel 5.7 menunjukan nyeri menstruasi pada siswi yang dilakukan terhadap 17 responden kelompok kontrol, tidak terdapat perbedaan secara signifikan antara nilai nyeri menstruasi sebelum diberikan intervensi teknik relaksasi steam inhalation tanpa menggunakan aromaterapi lemon (citrus) terhadap penurunan nyeri menstruasi dengan nilai $\mathrm{p}$ value 1,000 lebih besar dari 0,05, maka Ho ditolak.

Hasil penelitian ini sejalan dengan penelitian yang telah dilakukan oleh Suwanti (2018) bahwa rata-rata nilai nyeri menstruasi sebelum dilakukan intervensi dengan menggunakan aromaterapi lemon (citrus) 4,95. Nilai nyeri menstruasi sesudah dilakukan intervensi dengan menggunakan aromaterapi lemon (citrus) 2,65. Yang berarti ada pengaruh aromaterapi lemon (citrus) terhadap penurunan nyeri menstruasi.

Aromaterapi adalah salah satu teknik pengobatan atau perawatan menggunakan bau-bauan yang menggunakan esensial aromaterapi (Dewi, 2013). Aromaterapi adalah istilah modern untuk praktik yang sudah dilakukan ribuan tahun yang lalu, yang merupakan penatalaksanaan perawatan dan pengobatan menggunakan minyak esensial (Sunito, 2010). Aromaterapi adalah suatu metode dalam relaksasi yang menggunakan minyak esensial dalam pelaksanaanya berguna untuk meningkatkan kesehatan fisik, emosi dan spirit seseorang (Koensoemardiyah, 2009).

Cara kerja bahan aromaterapi adalah melalui sistem sirkulasi tubuh dan indra penciuman, dimana bau merupakan suatu molekul yang mudah menguap apabila masuk ke rongga hidung melalui pernafasan. Melalui penghirupan pada aromaterapi, sebagian molekul-molekul akan masuk ke paru, kemudian molekul aromatik akan diserap oleh lapisan mukosa pada saluran pernafasan, baik pada bronkus atau pada cabang halus (bronchiole) dan terjadi pertukaran gas dalam alveoli. Molekul tersebut akan meningkatkan jumlah bahan aromatik yang ada kedalam tubuh. Minyak aromaterapi lemon mempunyai kandungan limeone 66-80 granil asetat, netrol, tripne 6$14 \%, \quad \alpha$ pinene $1-4$ dan mrcyne (Young,2011).

Limeone adalah komponen utama dalam senyawa kimia jeruk yang dapat menghambat sistem kerja prostaglandin sehingga dapat mengurai nyeri dan mengurangi rasa sakit. Aromaterapi ini bermanfaat untuk mengurangi ketegangan otot yang akan mengurangi tingat nyeri. Sebagian besar obat penghilang rasa sakit dan obat antiinflamasi mengurangi rasa sakit dan peradangan dengan mengendalikan enzim 
ini. Bisa disimpulkan bahwa limeone dalam lemon (cytrus) akan mengontrol prstagladin dan mengurangi rasa nyeri (Namazi, dkk., 2014). Wong juga mengatakan zat yang terdapat dalam lemon adalah salah satunya zat linalool yang berguna untuk menstabilkan system saraf sehingga dapat menimbulkan efek tenang bagi siapapun yang menghirupnya (Kozier \& Berman, 2010).

Aroma yang diolah dan konvenrsikan oleh tubuh menjadi suatu aksi dengan pelepasan substansi neurokimia berupa zat endhoprin dan serotonin. Sehingga berperngaruh langsung pada otak untuk memberikan reaksi yang membuat perubahan fisiologis pada tubuh. Aromaterapi yang dihirup akan ditransferkan kepusat penciuman yang berada pada pangkal otak. Pada tempat ini sel neuron akan menafsirkan bau tersebut dan akan mengantarkan kesistem limbic. Dari system limbic pesan tersebut akan dihantarkan kehipotalamus, dihipotalamus, seluruh system minyak esensial tersebut akan diantar oleh system sirkulasi dan agen kimia kepada tubuh yang membutuhkan (Setyoadi, 2011).

Berdasarkan hasil penelitian diatas diketahui bahwa sebagian besar responden pada kelompok intervensi mengalami perubahan tingkat nyeri setelah diberikan intervensi teknik relaksasi steam inhalation dengan menggunakan aromaterapi lemon, karena dalam aroma terapi lemon terdapat senyawa kimia yang bernama limeon dan linalool. Limeone ini berfungsi untuk menghambat sistem kerja prostaglandin dimana yang telah diketahui bahwa prostaglandin akan merangsang penekanan otot, kontraksi otot rahim dan penekanan pembuluh darah. Sedangkan zat linalool berfungsi untuk menstabilkan sistem saraf yang akan menimbulkan efek tenang. Pada kelompok kontrol diketahui bahwa responden tidak mengalami perubahan tingkat nyeri karena uap air panas berfungsi untuk membuka pori-pori, mengendurkan otot-otot. Terapi menggunakan teknik Steam inhalation biasanya akan dikombinasikan dengan menggunakan minyak kayu putih atau minyak essential oil.

\section{KESIMPULAN}

Hasil penelitian ini menunjukkan adanya Pengaruh Pemberian Aroma Terapi Lemon (Cytrus) Terhadap Penurunan Nyeri Dismenore Pada Siswi Remaja di SMAN 1 SUNGAI AMBAWANG dengan nilai $\mathrm{p}=0,025$. Berdasarkan penelitian ini, peneliti menyarankan kepada pembaca untuk dapat menggunakan aromaterapi lemon untuk alternatif mengatasi permasalahan kesehatan yang muncul. Selain itu, bagi peneliti selanjutnya diharapkan mampu mengeksplor lebih dalam terkait manfaat lemon dalam mengatasi permasalahan kesehatan.

\section{UCAPAN TERIMA KASIH}

1. Ibu Fajar Yousriatin, M. Kes selaku Ketua STIKes YARSI Pontianak

2. Ibu Ns. Yunita Dwi Anggreini, M.Kep selaku ketua program studi Ners Keperawatan Stikes Yarsi Pontianak

3. Seluruh staf dan dosen yang telah banyak membantu kelancaran penyelesaian laporan penelitian di STIKes Yarsi Pontianak.

4. Keluarga tercinta terutama bapak dan ibu saya yang telah banyak membantu baik secara materil, moril dan do'a untuk keberhasilan penulisan laporan penelitian ini.

5. Rekan-rekan yang namanya tidak dapat disebutkan satu persatu yang telah banyak membantu baik secara moril maupun spiritual sehingga laporan ini dapat diselesaikan. 


\section{REFERENSI}

Abreu-Sánchez, A., Parra-Fernández, M. L., Onieva-Zafra, M. D., Ramos-Pichardo, J. D., \& Fernández-Martínez, E. (2020). Type of Dysmenorrhea, Menstrual Characteristics and Symptoms in Nursing Students in Southern Spain. Healthcare, $\quad 8(3), \quad 302$. https://doi.org/10.3390/healthcare 8030 302

Abubakar, U., Zulkarnain, A. I., Samri, F., Hisham, S. R., Alias, A., Ishak, M., Sugiman, H., \& Ghozali, T. (2020). Use of complementary and alternative therapies for the treatment of dysmenorrhea among undergraduate pharmacy students in Malaysia: A cross sectional study. BMC Complementary Medicine and Therapies, 20(1). https://doi.org/10.1186/s12906-02003082-4

Al-Quadh, T. S., Zahra, U., Rehman, R., Rehman, R., Sadique, S., Nisar, S., AlQudah, T. S., \& Tahtamouni, R. W. (2018). Lemon as a source of functional and medicial inggrident: A review. International Journal of Chemical and Biochemical Science, 14(January), 111.

Ali, B., Al-Wabel, N. A., Shams, S., Ahamad, A., Khan, S. A., \& Anwar, F. (2015). Essential oils used in aromatherapy: A systemic review. Asian Pacific Journal of Tropical Biomedicine, 5(8), 601-611. https://doi.org/10.1016/j.apjtb.2015.05. 007

Berkley, K. (2013). Primary dysmenorrhea: an urgent mandate. Pain, 1(1).

Bezuidenhout, S., \& Mahlaba, K. J. (2018). Dysmenorrhoea : an overview. January.

Dewi, Iga Prima. (2013). Aromaterapi Lavender Sebagai Media Relaksasi. Universitas Udayana : Bagian Farmasi Fakultas Kedokteran.

Jo, J., \& Lee, S. H. (2018). Heat therapy for primary dysmenorrhea: A systematic review and meta-analysis of its effects on pain relief and quality of life. Scientific Reports, 8(1). https://doi.org/10.1038/s41598-01834303-z

Koensoemardiyah. (2009). A-Z Aromaterapi untuk Kesehatan, Kebugaran dan Kecantikan. Yogyakarta : Lily Publisher.

Kozier,B.,Glenora Erb, Audrey Berman dan Shirlee J.Snyder. (2010). Buku Ajar Fundamental Keperawatan (Alih bahasa : Esty Wahyu ningsih, Devi yulianti, yuyun yuningsih. Dan Ana lusyana ). Jakarta :EGC.

Larasati, T., \& Alatas, F. (2016). Dismenore Primer dan Faktor Risiko Dismenore Primer pada Remaja. Majority, 5(3), 7984.

Namazi, M., Ali Akbari, S. A., Mojab, F., Talebi, A., Majd, H. A., \& Jannesari, S. (2014). Effects of citrus Aurantium (bitter orange) on the severity of firststage labor pain. Iranian Journal of Pharmaceutical Research, 13(3), 10111018.

https://doi.org/10.22037/ijpr.2014.1553

Petraglia, F., Bernardi, M., Lazzeri, L., Perelli, F., \& Reis, F. M. (2017). Dysmenorrhea and related disorders. F1000Research, 6(0), 1-7. https://doi.org/10.12688/f1000research. 11682.1

Setyoadi. (2011). Terapi Modalitas Keperawatan Pada Klien Psikogeratik. Jakarta: EGC.

Sharghi, M., Mansurkhani, S. M., AshtaryLarky, D., Kooti, W., Niksefat, M., Firoozbakht, M., Behzadifar, M., Azami, M., Servatyari, K., \& Jouybari, L. (2019). An update and systematic review on the treatment of primary dysmenorrhea. Jornal Brasileiro de Reproducao Assistida, 23(1), 51-57. 
https://doi.org/10.5935/15180557.20180083

Sunito, dkk, (2010). Aroma Alam Untuk Kehidupan. Jakarta : PT Raketindo Primamedia mandiri.

Vilšinskaitè, D. S., Vaidokaitè, G., Mačys, Ž., \& Bumbuliené, Ž. (2019). The risk factors of dysmenorrhea in young women. Wiadomosci Lekarskie
(Warsaw, Poland: 1960), 72(6), 11701174.

https://doi.org/10.36740/wlek20190610 2

Young, G. (2011). Essencial Oil Pocket Reference 5th ed. Amazon: Life Science Pubhlising. 